\title{
Autotransplantation of Immature Third Molars and Orthodontic Treatment After En Bloc Resection of Conventional Ameloblastoma
}

\author{
Rafael Lima Verde Osterne, DDS, MSc, ${ }^{\star} J$ José Jeová Siebra Moreira Neto, DDS, MSc, PhD, † \\ Augusto Darwin Moreira de Araújo Lima, DDS, MSc, \\ and Renato Luiz Maia Nogueira, DDS, MSc, PbD $\S$
}

\begin{abstract}
Ameloblastoma treatment can lead to significant bone defects; consequently, oral rehabilitation can be challenging. We present the case of a 14-year-old girl diagnosed with a conventional ameloblastoma in the mandible who was treated using en bloc resection and rehabilitated with autotransplantation of the immature third molars and orthodontic treatment. The lesion was in the region of the lower left canine and premolars, and en bloc resection resulted in a significant alveolar bone defect. Autotransplantation of the lower third molars to the site of the lower left premolars was performed. After 2 years, the upper left third molar was transplanted to the site of the lower left canine. During the orthodontic treatment period, considerable alveolar bone formation was observed in the region of the transplanted teeth, and roots developed. To the best of our knowledge, this is the first reported case of alveolar bone formation induction caused by tooth transplantation after ameloblastoma treatment.
\end{abstract}

(C) 2015 American Association of Oral and Maxillofacial Surgeons

J Oral Maxillofac Surg 73:1686-1694, 2015

Ameloblastoma is a benign odontogenic tumor of epithelial origin that represents 19.3 to $41.5 \%$ of all odontogenic tumors. ${ }^{1-6}$ Although benign, this lesion is locally aggressive and involves the mandible more frequently than the maxilla (at a ratio of 10:1). ${ }^{1}$ This tumor can arise from the enamel organs, the remains of dental lamina, basal cells of the oral mucosa, or epithelial cells in odontogenic cysts. Ameloblastoma is one of the most clinically significant odontogenic tumors.

Ameloblastoma occurs most frequently in the second to fourth decades of life. Although some investigators have stated that it has no gender predilection, ${ }^{3}$ ameloblastoma was more frequently diagnosed in females in some studies. ${ }^{1,7}$ The current classification of ameloblastoma includes 4 types, 3 of which are intraosseous and the last of which is a rare peripheral variant. Intraosseous ameloblastomas are classified as solid/multicystic or conventional ameloblastoma, unicystic ameloblastoma, or desmoplastic ameloblastoma. Solid/multicystic ameloblastoma is the most common variant, comprising 54 to $85 \%$ of all types. ${ }^{1,8}$

Intraosseous ameloblastomas are aggressive, slowgrowing lesions that can become very large and cause bone destruction. On a panoramic radiograph, conventional ameloblastoma can show unilocular or (more frequently) multilocular radiolucencies that
*Assistant Professor, Department of Pathology, Fortaleza University School of Medicine, Fortaleza, Brazil; PhD Student, Federal University of Ceara School of Dentistry, Fortaleza, Brazil.

†Associated Professor, Department of Dental Clinic, Discipline of Pediatric Dentistry, Federal University of Ceara School of Dentistry, Fortaleza, Brazil.

$\ddagger$ PhD Student, Department of Dental Clinic, Federal University of Ceara School of Dentistry, Fortaleza, Brazil.

$\S$ Associated Professor, Department of Dental Clinic, Discipline of Oral and Maxillofacial Surgery and Stomatology, Federal University of Ceara School of Dentistry, Fortaleza, Brazil; Oral and Maxillofacial

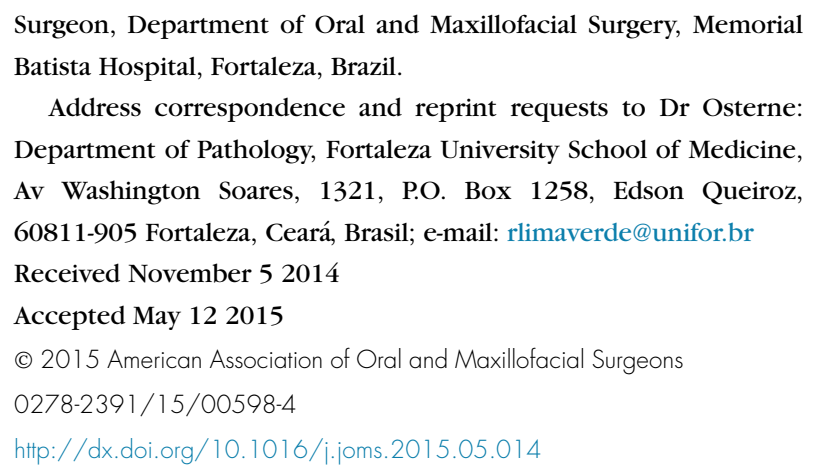
Department of Pathology, Fortaleza University School of Medicine, Av Washington Soares, 1321, P.O. Box 1258, Edson Queiroz, 60811-905 Fortaleza, Ceará, Brasil; e-mail: rlimaverde@unifor.br Received November 52014 Accepted May 122015 (C) 2015 American Association of Oral and Maxillofacial Surgeons 0278-2391/15/00598-4 http://dx.doi.org/10.1016/i.joms.2015.05.014 
are usually described as "soap bubbles." Radicular resorption is not an unusual finding, and nonerupted teeth can be involved in the lesion. ${ }^{9,10}$ Pain, swelling, malocclusion, and paresthesia are more frequently associated with larger lesions. ${ }^{\text {? }}$

Evidence from microscopy studies showed that the tumor cells of conventional ameloblastomas usually infiltrate the trabecular spaces beyond the radiographic extent of the tumor ${ }^{11}$; therefore, radical surgery is the treatment of choice for this variant. Large mandibular defects with or without significant facial disfiguration can result and occasionally require multiple surgeries and long-term treatment. Conventional ameloblastoma, therefore, represents a challenge in the field of oral rehabilitation.

We present the case of a 14-year-old girl who was diagnosed with a conventional ameloblastoma in the mandible. The patient was treated using en bloc resection and was rehabilitated with autotransplantation of 3 teeth with incomplete root formation and orthodontic treatment.

\section{Case Report}

A 14-year-old girl was referred to the oral and maxillofacial surgery department of the Hospital Batista Memorial because of an asymptomatic lesion in the mandible that was incidentally discovered on a panoramic radiograph taken for orthodontic treatment. Her medical history was not significant. The physical extraoral examination findings were unremarkable, and facial deformity was not observed. A physical intraoral examination revealed an asymptomatic and unobtrusive bone expansion near the lower left canine and premolars. A radiographic examination showed a well-defined multilocular radiolucent area with a "soap bubble" appearance (Fig 1). With the patient under local anesthesia, an incisional biopsy of the lesion was performed without complications. The histopathologic examination revealed a benign odontogenic lesion characterized by the presence of epithelial nests presenting with peripheral columnar cells with reversed polarity and hyperchromatic nuclei. The central cells were loosely arranged to resemble the stellate reticulum and occasionally presented with cysts. The stroma was composed of mature connective tissue. The final diagnosis was conventional ameloblastoma.

In September 2008, under general anesthesia, the patient underwent marginal en bloc resection of the lesion extending from the lower left canine to the lower left first molar. The postoperative period was uneventful; however, a substantial mandibular bone defect was created (Fig 2). In April 2009, oral rehabilitation was raised as a possibility, with autotransplantation of the lower third molar to the bone defect site.

Because of the lack of root development, the autotransplantation was not performed until March 2010. The lower third molars were transplanted to the first molar and second premolar regions, respectively.

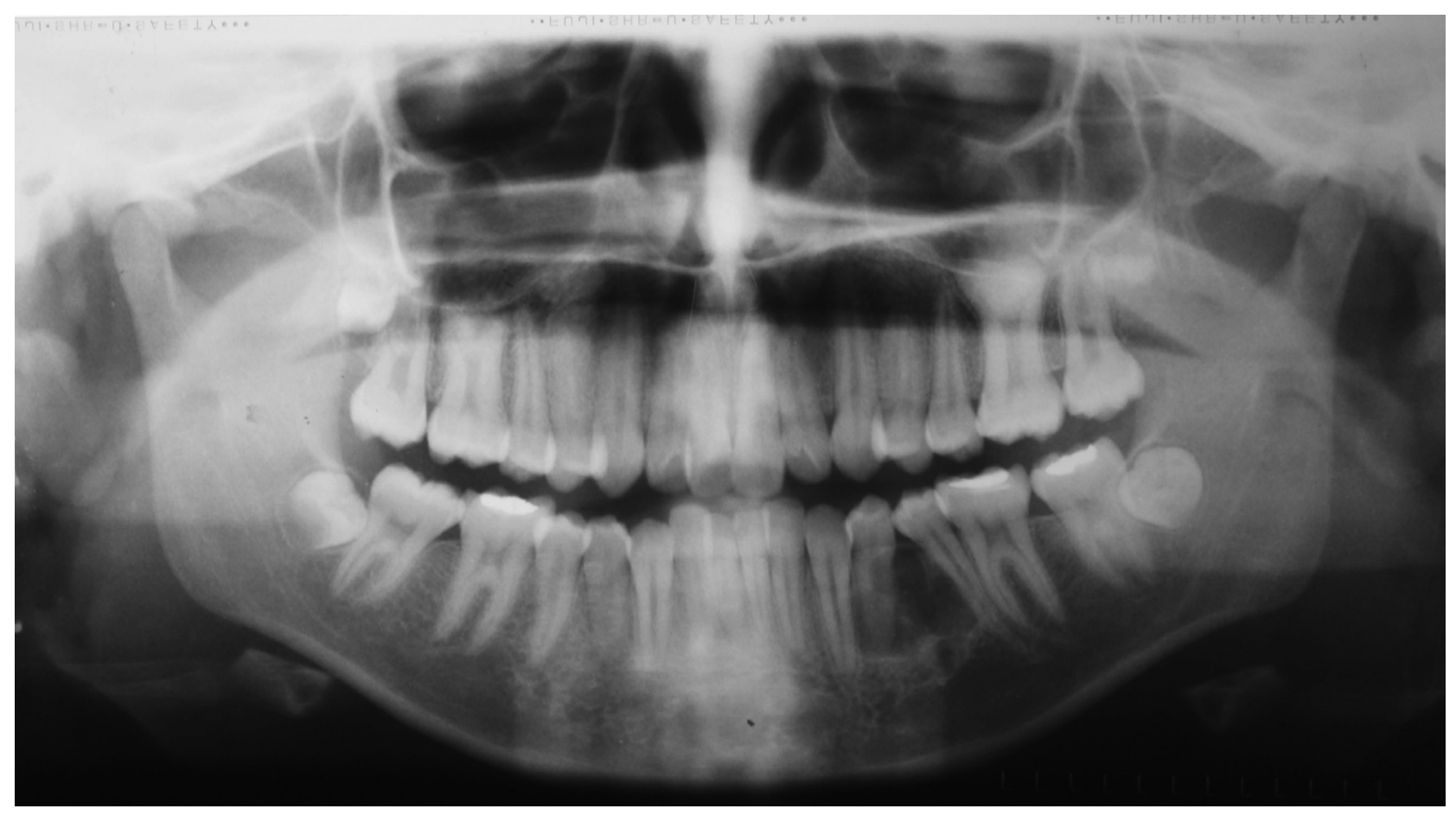

FIGURE 1. A radiograph showing a well-defined multilocular radiolucent area with a "soap bubble" appearance. 

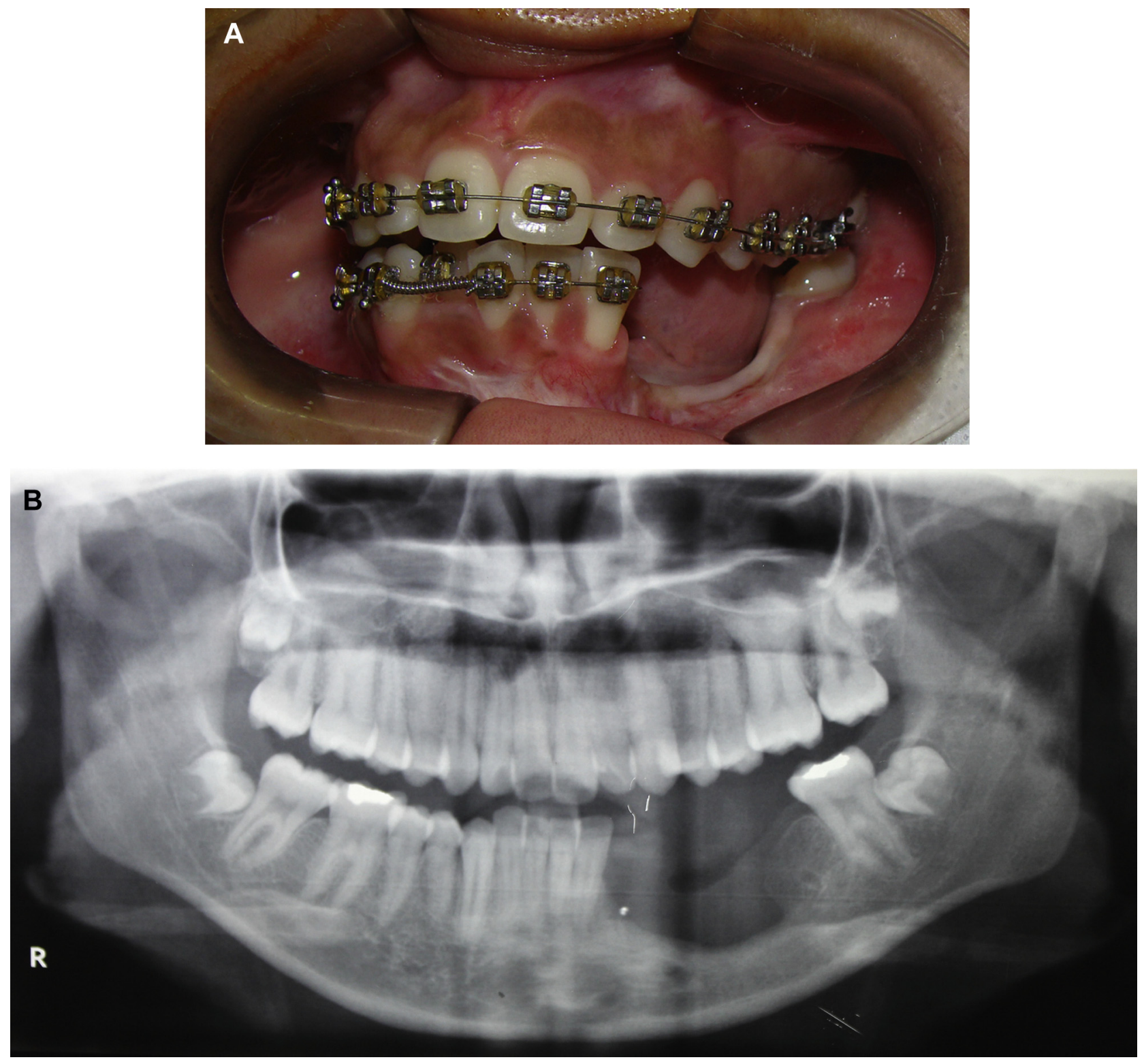

FIGURE 2. Mandibular bone defect after a marginal en bloc resection of the lesion extending from the lower left canine to the lower left first molar. A, Clinical intraoral view. B, Radiographic view.

Osterne et al. Teeth Autotransplantation After Treatment of Ameloblastoma. J Oral Maxillofac Surg 2015.

With the patient under local anesthesia, mucoperiosteal flaps were raised in the mandibular defect and third molar areas. The donor inferior third molars were carefully extracted using elevators (keeping the radicular part intact) and transplanted to the first molar and second premolar areas without extraoral storage. Because of the bone defects at the recipient site, no additional bone was removed to create a socket; instead, only a horizontal crestal incision was made, and the teeth were placed into the soft tissue. The transplanted teeth were splinted to the lower second molar with acid-etch composite resin. Inferior third molars showed approximately one third of the total root development; these teeth were left in infraoc- clusion. A liquid diet was recommended for 30 days. The postoperative period was uneventful; gingiva formed and attached, and the splint was removed approximately 60 days after transplantation. In September 2010, 6 months after transplantation and after visualization of initial bone formation, the transplanted teeth were released for orthodontic movement. After very slow orthodontic movement, both transplanted teeth were in occlusion (January 2011; Fig 3).

In April 2012, the upper left third molar was transplanted to the site of the lower left canine. The surgical technique and method of postoperative care were the same as those used with the first autotransplantation. 


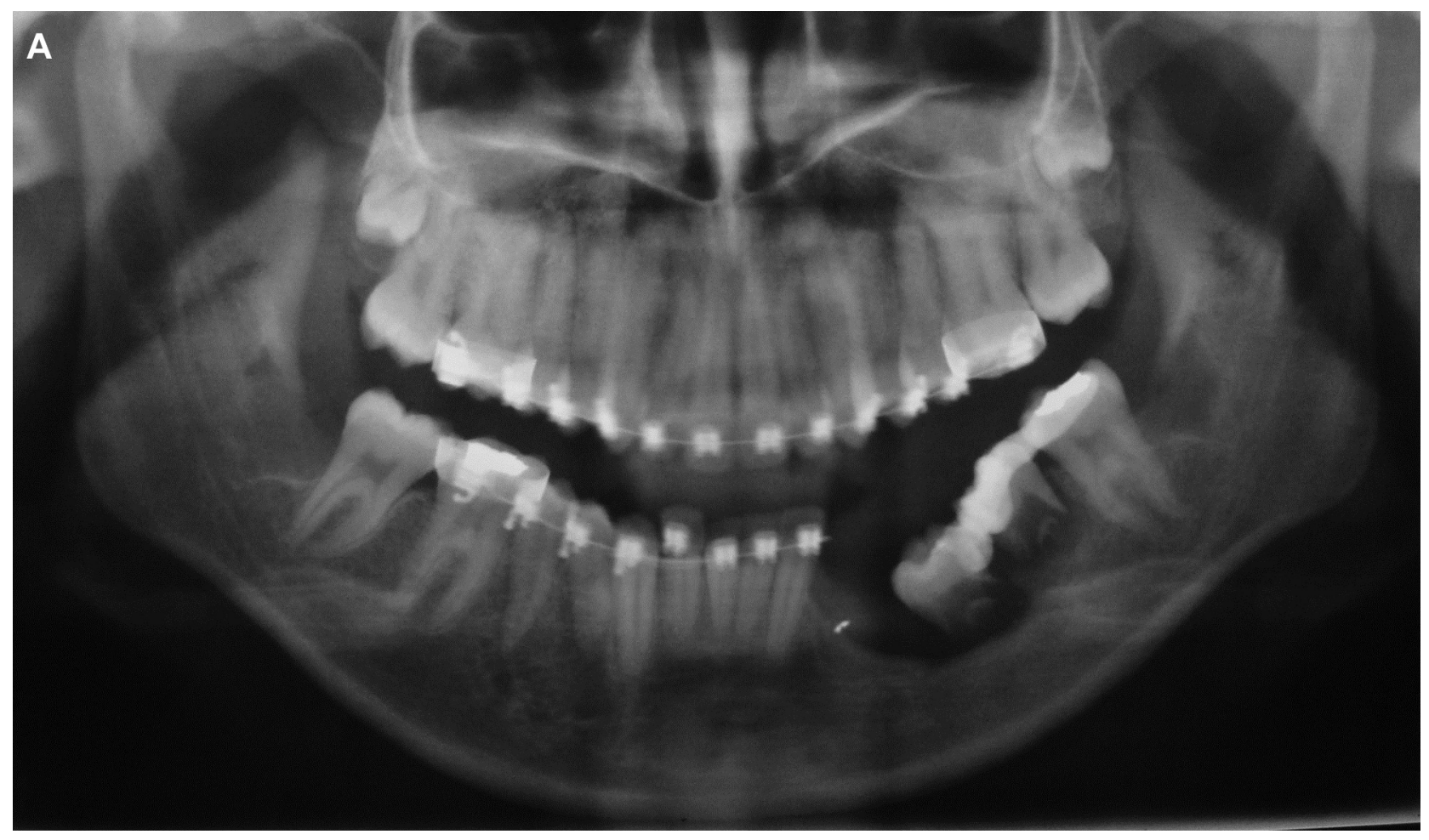

FIGURE 3. Radiographs after transplantation of the lower third molars to the region of the first molar and second premolar. A, Radiograph taken after 7 days. (Fig 3 continued on next page.)

Osterne et al. Teeth Autotransplantation After Treatment of Ameloblastoma. J Oral Maxillofac Surg 2015.

The upper left third molar was selected because of the more appropriate mesiodistal length, which adapted better to the receptor site. In December 2012, the transplanted tooth was released for orthodontic treatment with very slow movement (Fig 4).

During orthodontic treatment, considerable alveolar bone formation was observed in the region of the transplanted teeth (Fig 5). Root development occurred in all the transplanted teeth; however, the root growth of the tooth transplanted into the canine region was decreased compared with that of the other transplanted teeth. All the transplanted teeth were in masticatory function with no discomfort, mobility, or pathologic conditions. The gingival contour, color, and depth of the pocket were all normal. Also, all the transplanted teeth responded to thermal pulp testing, although partial pulp obliteration was present. In July 2014, the orthodontic treatment was completed.

\section{Discussion}

Conventional ameloblastoma has a high potential for recurrence after curettage, and the radiographic margin of the lesion will not correspond to the histologic margin. The tumor is usually found 2 to $8 \mathrm{~mm}$ (mean 4.5) beyond the radiographic margin; thus, radical surgery with a bone margin of 1 to $1.5 \mathrm{~cm}$ is rec- ommended. ${ }^{11}$ When doubt exists regarding the bone margins, a radiograph of the resected surgical specimen or the use of a frozen section biopsy can assist the surgeon. ${ }^{11}$ The jaw is important, not only from a functional viewpoint regarding dentition and occlusion, but also for facial aesthetic reasons. The face has a central importance in daily interactions. Thus, whenever possible, en bloc resection with preservation of the base of the mandible (which could assist in future oral rehabilitation) should be planned for mandibular odontogenic tumors.

Several methods can be used in oral rehabilitation, including prosthodontics or dental implants, which can be preceded by bone grafts or osteogenesis distraction. ${ }^{12}$ However, patients are not always candidates for these procedures because of age-related or financial reasons. In such cases, autotransplantation could be an option. ${ }^{13}$

Most investigators have stated that a tooth transplantation candidate should have one-half to threefourths root formation to facilitate tooth stabilization for periodontal healing and open the apex for pulp revascularization. ${ }^{14-19}$ However, success can be achieved in cases of one-third or complete root formation. . $^{21}$

To avoid extending cell damage to the root surface, the tooth should be removed gently from the donor 


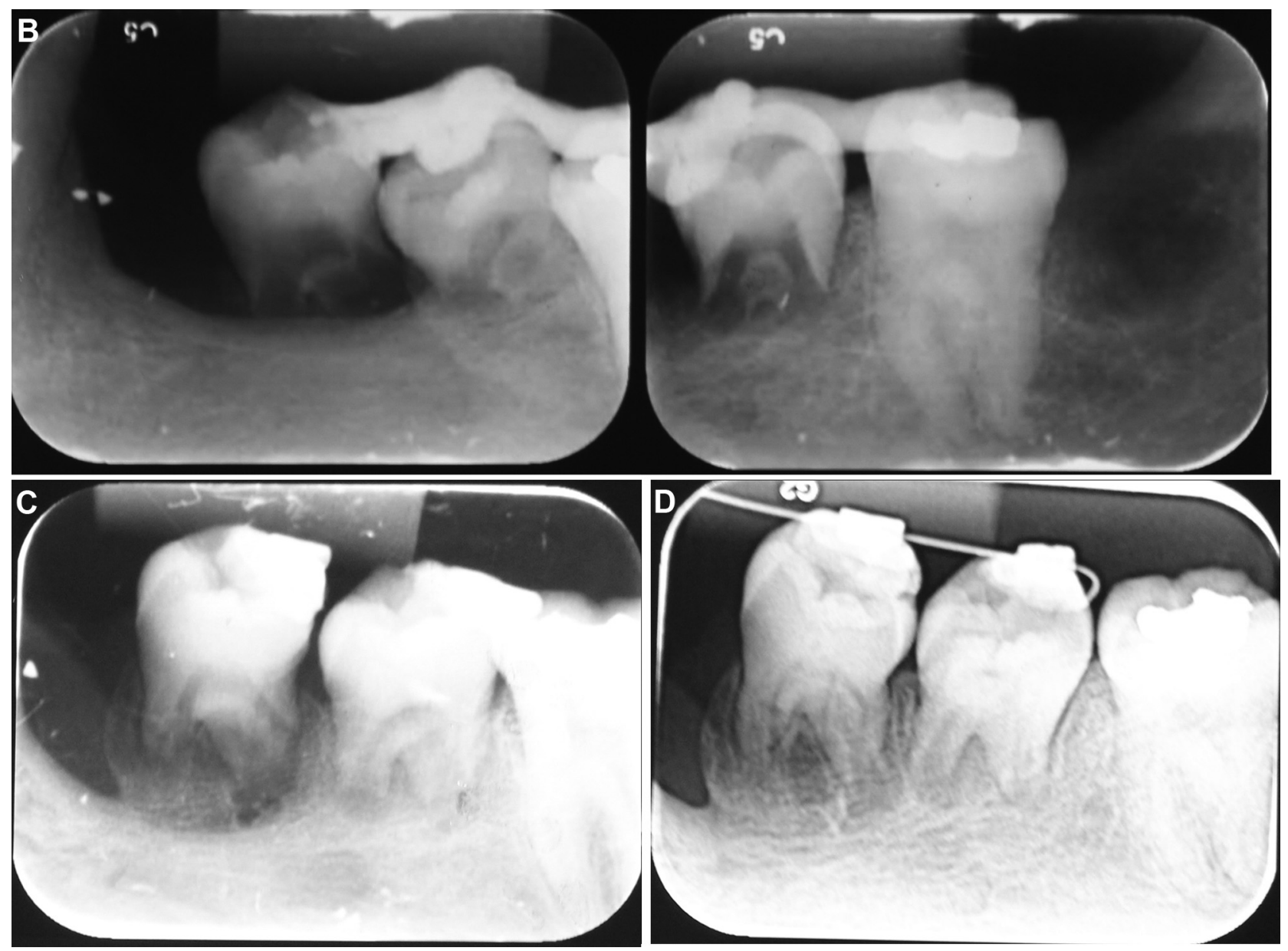

FIGURE 3 (cont'd). B, Radiograph taken after 60 days. C, Radiograph taken after 6 months. D, Radiograph taken 1 year after transplantation showing considerable alveolar bone formation.

Osterne et al. Teeth Autotransplantation After Treatment of Ameloblastoma. J Oral Maxillofac Surg 2015.

site without extensive osteotomies or severe dislocations. ${ }^{22}$ Minimizing the duration that a donor tooth is out of the mouth and the duration of root manipulation during autotransplantation are keys for success; however, in some cases, dentoalveolar ankylosis, root resorption, or even compromised root growth can occur. In the present patient, all the transplanted teeth had approximately one-third root formation, and the autotransplantations were considered successful because undesirable complications were not observed, the roots developed, and the teeth were in occlusion and functional. Damage to the periodontal ligament, root resorption, and pulp necrosis are more likely to occur in teeth with complete root formation than in teeth transplanted during root development. ${ }^{16-19}$

The minimal apical foramen diameter needed to obtain vital pulp in an autotransplanted tooth is $1 \mathrm{~mm}$. In cases with a smaller diameter, pulp revascularization will be unpredictable, although an animal study demonstrated that in 10 teeth with apical diameters varying from 0.24 to $0.53 \mathrm{~mm}, 50 \%$ presented with vital tissue in more than two-thirds of the pulp chamber. ${ }^{23}$ In the present patient, all the transplanted teeth were in the root development period; thus, the roots had an open apex with a good chance of apical revascularization and pulp vitality. Endodontic treatment is not usually necessary in cases of an open apex unless clinical or radiologic symptoms of periapical inflammation or root resorption occur.

Tooth transplantation can be performed at a fresh extraction site; however, when complete postextraction regeneration of the alveolar socket has occurred, a recipient site can be created with burs. Some investigators have demonstrated similar results for transplantations into both prepared and fresh sockets. ${ }^{24}$ In atrophied jaw sections, free bone grafts and a splitting osteotomy of the alveolar process can be performed during tooth transplantation; however, these procedures have had a lower success rate. ${ }^{24}$ In the 


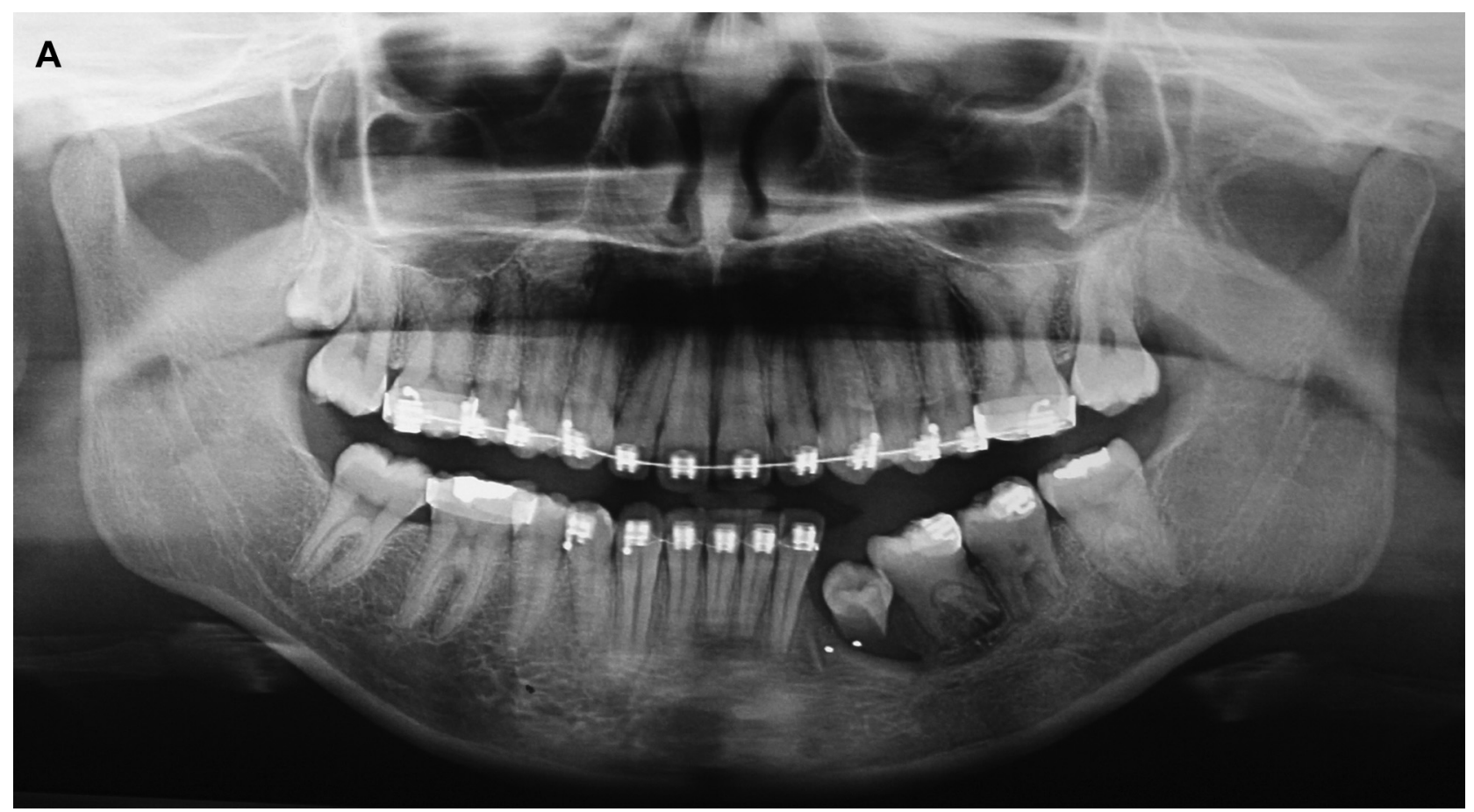

FIGURE 4. Radiographs after transplantation of the upper third molar to the canine region. A, Radiographs taken after 7 days. (Fig 4 continued on next page.)

Osterne et al. Teeth Autotransplantation After Treatment of Ameloblastoma. J Oral Maxillofac Surg 2015.

present patient, significant loss of the alveolar process had occurred, and burs were not used to create a socket. Instead, the teeth were placed into the soft tissue and splinted to the distal tooth with acid-etch composite resin.

To our knowledge, this is the first case of alveolar bone regeneration in mandibular bone defects after ameloblastoma resection and tooth autotransplantation without bone grafting. Considerable alveolar bone formation was observed after transplantation. A previous study showed that tooth transplantation can induce bone formation. ${ }^{25}$ Additionally, a recent in vivo study demonstrated that Hertwig's epithelial root sheath cells can stimulate osteogenic differentiation of dental follicle cells by way of cell to cell communication $^{26}$ and could play a role in alveolar bone formation. Tooth autotransplantation after ameloblastoma treatment was described by Lim and Chun $^{27}$ in an 18-year-old woman who presented with a unicystic ameloblastoma. The patient was treated using enucleation and immediate bone grafting, followed by autotransplantation and orthodontic treatment.

In addition to its predictability, tooth autotransplantation can offer a good aesthetic result, especially in the germ phase. Tooth autotransplantation can also induce alveolar bone growth and re-establish the alveolar process. ${ }^{25,28-30}$ The risk of ankylosis after transplantation of an unerupted tooth germ is reduced, because the dental follicle protects the root surface from injury. Additionally, transplantation of unerupted teeth has been associated with a high likelihood of pulp revascularization, generation of normal periodontal tissue, and root growth. ${ }^{31}$ It has previously been shown that apical pulp-derived cells have the potential to induce hard tissue formation, suggesting that a tooth with an immature apex is an effective source of cells for hard tissue/periodontal complex regeneration, ${ }^{32,33}$ and some clinical results have supported this finding. ${ }^{25,31}$ Bone defects secondary to trauma or resulting from surgical resection could benefit from the autotransplantation of immature teeth, even during maxillomandibular development.

Several techniques can be used for the rehabilitation of mandibular defects. The use of dental implants or fixed prosthodontics during maxillomandibular development could interfere with bone growth, because osteointegrated implants will not grow with the patient's changing jaw, resulting in an infraocclusion. Osteogenic distraction could be used, although it has usually been associated with greater morbidity than that with tooth transplantation. Additionally, it requires longer follow-up periods and greater patient cooperation, and a risk exists of deviation of the distraction vector. ${ }^{34}$ Recombinant human bone morphogenetic protein 2 could be another option; however, this method is 

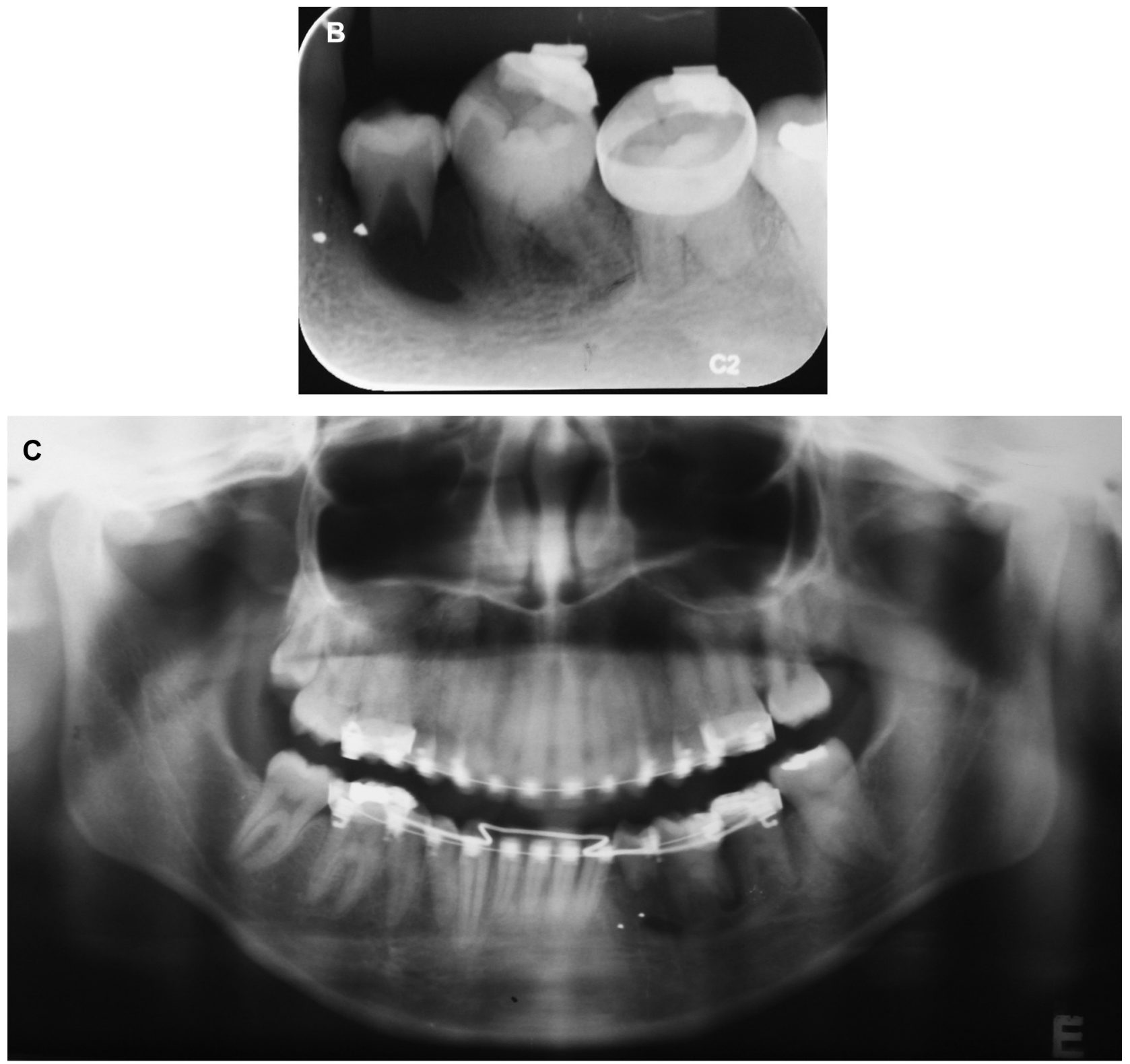

FIGURE 4 (cont'd). B, Radiographs taken after 7 days. C, Radiograpsh taken at 15 months after transplantation showing alveolar bone formation in the canine region.

Osterne et al. Teeth Autotransplantation After Treatment of Ameloblastoma. J Oral Maxillofac Surg 2015.
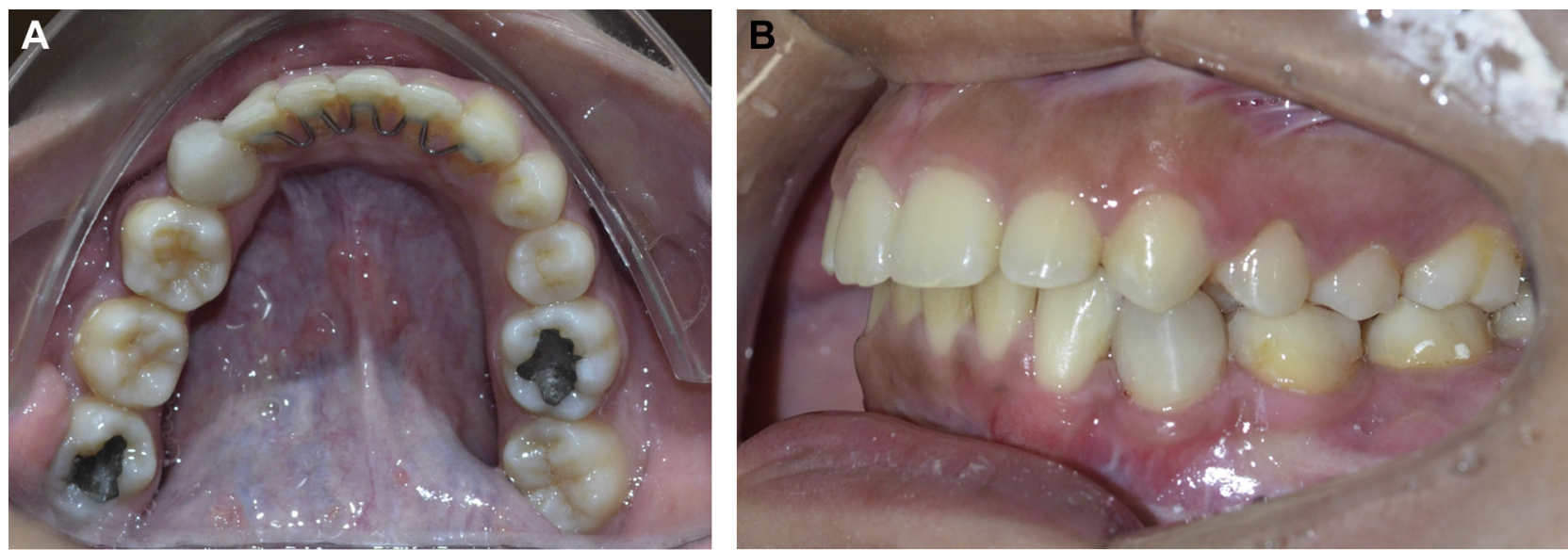

FIGURE 5. $A, B$, Clinical intraoral views showing all transplanted teeth in occlusion. (Fig 5 continued on next page.) Osterne et al. Teeth Autotransplantation After Treatment of Ameloblastoma. J Oral Maxillofac Surg 2015. 

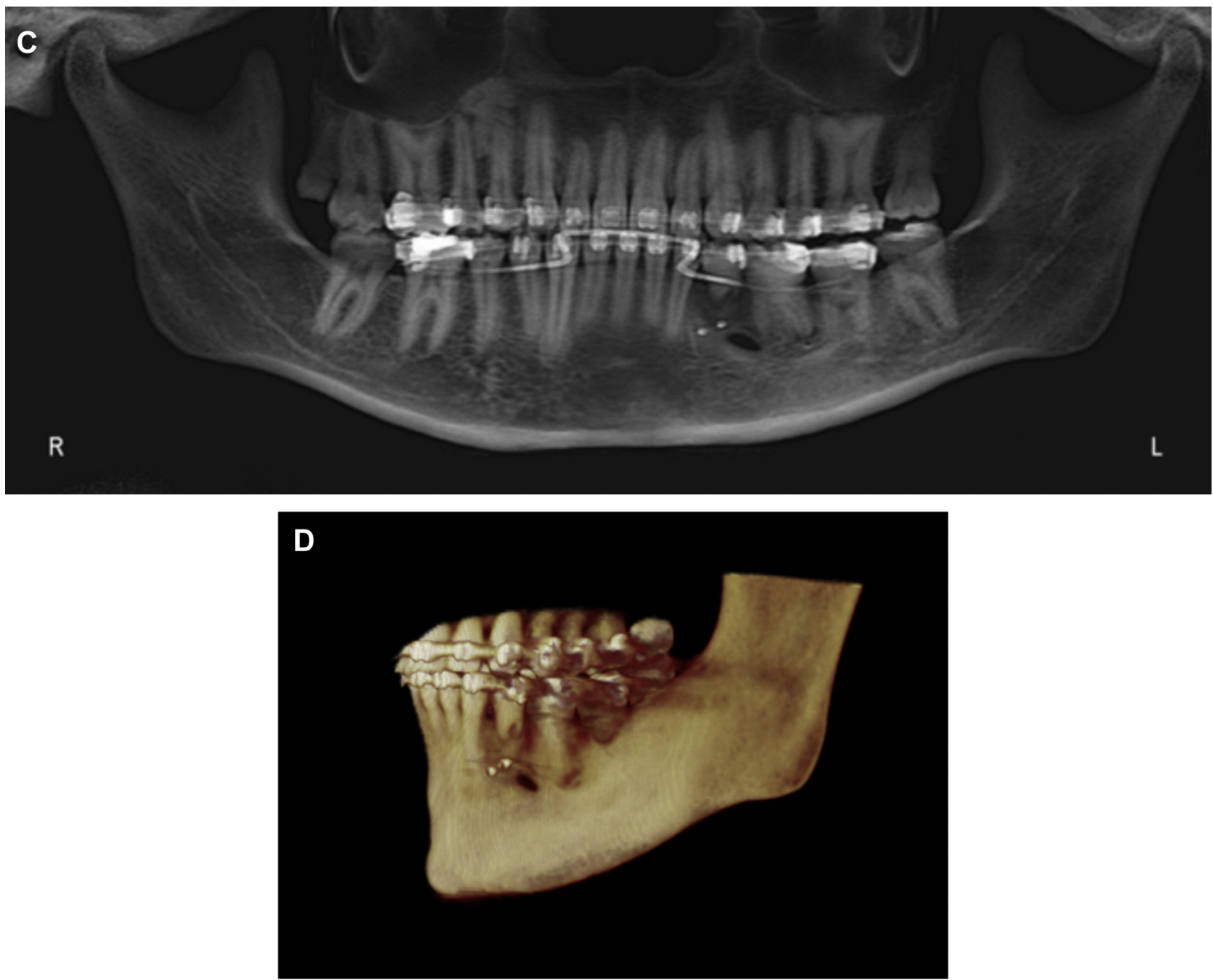

FIGURE 5 (cont'd). C, Radiograph showing alveolar bone formation and continuous root formation of all teeth with the exception of partial formation of the tooth transplanted to the canine region. $D$, Three-dimensional reconstruction of the mandible showing alveolar bone formation. Osterne et al. Teeth Autotransplantation After Treatment of Ameloblastoma. J Oral Maxillofac Surg 2015.

more expensive, and after bone formation, the use of dental implants or fixed prosthodontics would be necessary.

Accordingly to Kumar et al, ${ }^{13}$ tooth transplantation can be considered successful if the tooth is fixed in its socket without residual inflammation, masticatory function is satisfactory with no discomfort, the tooth is not mobile, no pathologic conditions are apparent from radiographic examinations, the lamina dura is radiographically normal, the tooth shows radiographic evidence of root growth and pulpal regeneration, and the depth of the pocket, gingival contour, and gingival color are all normal. In the present patient, these criteria for successful autotransplantation were fulfilled, with the exception of the partial root growth in first premolar, and all transplanted teeth responded to thermal pulp testing, although partial pulp obliteration was present. Even if this tooth were to be lost in the future, the bone gain that occurred in the region would facilitate rehabilitation at the site.

In conclusion, tooth autotransplantation is well suited to growing individuals. In the case of failure, dental implants can be inserted in patients before the completion of pubertal growth. Long-term follow-up should be emphasized in the present patient owing to the possibility of ameloblastoma recurrence and root resorption of the transplanted teeth.

\section{References}

1. Osterne RL, Brito RG, Alves AP, et al: Odontogenic tumors A 5-year retrospective study in a Brazilian population and analysis of 3406 cases reported in the literature. Oral Surg Oral Med Oral Pathol Oral Radiol Endod 111:474, 2011

2. Gaitán-Cepeda LA, Quezada-Rivera D, Tenorio-Rocha F, LeyvaHuerta ER: Reclassification of odontogenic keratocyst as tumour: Impact on the odontogenic tumours prevalence. Oral Dis $16: 185,2010$ 
3. Avelar RL, Antunes AA, Santos T, et al: Odontogenic tumors: Clinical pathology study of 238 cases. Braz J Otorhinolaryngol 74 : 668,2008

4. Jing W, Xuan M, Lin Y, et al: Odontogenic tumours: A retrospective study of 1642 cases in a Chinese population. Int J Oral Maxillofac Surg 36:20, 2007

5. Luo HY, Li TJ: Odontogenic tumors: A study of 1309 cases in a Chinese population. Oral Oncol 45:706, 2009

6. Tawfik MA, Zyada MM: Odontogenic tumors in Dakahlia, Egypt: Analysis of 82 cases. Oral Surg Oral Med Oral Pathol Oral Radiol Endod 109:e67, 2010

7. Fernandes AM, Duarte EC, Pimenta FJ, et al: Odontogenic tumors: A study of 340 cases in a Brazilian population. J Oral Pathol Med 34:583, 2005

8. Buchner A, Merrell PW, Carpenter WM: Relative frequency of central odontogenic tumors: A study of 1,088 cases from Northern California and comparisons to studies from other parts of the world. J Oral Maxillofac Surg 64:1343, 2006

9. Barnes L, Eveson JW, Reichart P, Sidransky D (eds): World Health Organization Classification of Tumours. Pathology and Genetics of Head and Neck Tumours. Lyon, IARC Press, 2005, pp 296-300

10. Fregnani ER, da Cruz Perez DE, de Almeida OP, et al: Clinicopathological study and treatment outcomes of 121 cases of ameloblastomas. Int J Oral Maxillofac Surg 39:145, 2010

11. Carlson ER, Marx RE: The ameloblastoma: Primary, curative surgical management. J Oral Maxillofac Surg 64:484, 2006

12. O'Fearraigh P: Review of methods used in the reconstruction and rehabilitation of the maxillofacial region. J Ir Dent Assoc $56: 32,2010$

13. R1 Kumar, Khambete N, Priya E: Successful immediate autotransplantation of tooth with incomplete root formation: Case report. Oral Surg Oral Med Oral Pathol Oral Radiol 115:e16, 2013

14. Henrichvark C, Neukam FW: Indikation und Ergebnisse der autogenen Zahntransplantation. Dtsch Zahnarztl Z 42:194, 1987

15. Kallu R, Vinckier F, Politis C, et al: Tooth transplantations: Descriptive retrospective study. Int J Oral Maxillofac Surg 34:745, 2005

16. Andreasen JO, PaulsenH U, Yu Z: A long-term study of 370 autotransplanted premolars: Part I-Surgical procedures and standardized techniques for monitoring healing. Eur J Orthod 12:3, 1990

17. Andreasen JO, Paulsen HU, Yu Z, Schwartz O: A long-term study of 370 autotransplanted premolars: Part II-Tooth survival and pulp healing subsequent to transplantation. Eur J Orthod 12:14, 1990

18. Andreasen JO, Paulsen HU, Yu Z, Schwartz O: A long-term study of 370 autotransplanted premolars: Part III-Periodontal healing subsequent to transplantation. Eur J Orthod 12:25, 1990

19. Andreasen JO, Paulsen HU, Yu Z, Bayer T: A long-term study of 370 autotransplanted premolars: Part IV-Root development subsequent to transplantation. Eur J Orthod 12:38, 1990
20. Yoshino K, Kariya N, Namura D, et al: Survival rate in autotransplanted premolars with complete root formation: A retrospective clinical survey. Bull Tokyo Dent Coll 54:27, 2013

21. Lai FS: Autotransplantation of an unerupted wisdom tooth germ without its follicle immediately after removal of an impacted mandibular second molar: A case report. J Can Dent Assoc 75: 205, 2009

22. Schütz S, Beck I, Kühl S, Filippi A: Results after wisdom tooth transplantation: A retrospective study. Schweiz Monatsschr Zahnmed 123:303, 2013

23. Laureys WG, Cuvelier CA, Dermaut LR, De Pauw GA: The critical apical diameter to obtain regeneration of the pulp tissue after tooth transplantation, replantation, or regenerative endodontic treatment. J Endod 39:759, 2013

24. Bauss O, Engelke W, Fenske C, et al: Autotransplantation of immature third molars into edentulous and atrophied jaw sections. Int J Oral Maxillofac Surg 33:558, 2004

25. Hjortdal O, Bragelien J: Induction of jaw bone formation by tooth autotransplantation. Nor Tannlaegeforen Tid 88:319, 1978

26. Yang Y, Ge Y, Chen G, et al: Hertwig's epithelial root sheath cells regulate osteogenic differentiation of dental follicle cells through the Wnt pathway. Bone 63:158, 2014

27. Lim WH, Chun YS: Orthodontic treatment combined with autotransplantation after removal of ameloblastoma. Am J Orthod Dentofacial Orthop 135:375, 2009

28. Lima JP, Neto JJ, Beltrão HC, et al: Esthetic considerations for reshaping of autotransplanted premolars replacing maxillary central incisors: A case report. Dent Traumatol 25:631, 2009

29. Maia RL, Vieira AP: Auto-transplantation of central incisor with root dilaceration. Technical note. Int J Oral Maxillofac Surg 34: 89, 2005

30. Czochrowska EM, Stenvik A, Zachrisson BU: The esthetic outcome of autotransplanted premolars replacing maxillary incisors. Dent Traumatol 18:237, 2002

31. Plakwicz P, Wojtaszek J, Zadurska M: New bone formation at the site of autotransplanted developing mandibular canines: A case report. Int J Periodontics Restorative Dent 33:13, 2013

32. Abe S, Yamaguchi S, Watanabe A, et al: Hard tissue regeneration capacity of apical pulp derived cells (APDCs) from human tooth with immature apex. Biochem Biophys Res Commun 371:90, 2008

33. Xu L, Tang L, Jin F, et al: The apical region of developing tooth root constitutes a complex and maintains the ability to generate root and periodontium-like tissues. J Periodontal Res 44:275, 2009

34. Flores-Espinosa JA, Romero-Flores J: Osteogenesis bifocal distraction as an alternative of mandibular reconstruction: A case report. Rev Med Inst Mex Seguro Soc 49:659, 2011 